\title{
The latest methodological approaches in the spatial development of Ukrainian cities
}

Abstract

The article deals with topical issues of the development of the theory and practice of modern urban development in Ukraine. The necessity of the newest approaches in the sphere of urban designing is convincedly presented here. The application of dynamic methodology of permanent spatial (urban planning) on the basis of geoinformation technologies is proposed.

Ker words: sustainable development, swor anysis

One of the main theoretical and practical problems of modern urban development in Ukraine is the lack of methodologica evelopments concerning spatial development prospective and planning organizat separate parts that are in stagnation or are characterized by significant economic, demographic decline. Task planning cols and their implementation through spatial planning at the city level show the backlog during last 15-20 years from the urgent needs demonstrated by modern European tendencies. Urban planning in Ukraine is burdened with the history of a centralized planned economy. It is not flexible enough to respond to changing market conditions and to become an effective tool to form the urban space.

Objectively, at all three levels of planning process in Ukraine (macro level - national, meso level - regional, micro level - local (city) level) there is no general modern methodologica approach that would ensure the sustainable development of territories and individual cities. As some certain threats should be considered that the existing planning system in Ukraine is unable to support adequately the implementation of strateges refecting the realities of time been - reducing population and its aging againt the backdrop of economic downturn. Existing city plans are in line with national growth policis, and the fore the generat increase of housing stock pond the and the for the gener alivity are expected ies, despite the different conditions on local level.

1992, Ukraine joined the UN strategic Agenda 21, signed number of international treaties and agreements that oblige the country's government structures to develop on the principles of sustainable development, since sustainable development is a fundamental objective of the European Union. Sustainable Development Initiative (SCI), Concept of Sustainable Development of Settlements in Ukraine (1999), Leipzig Charter "European Cities for Sustainable Development" (2007), Ukraine 2020 Sustainable Development Strategy (2015) and anumer of other international and nationa 政 modern development of territories and settlethe the economy, the domination of resource and

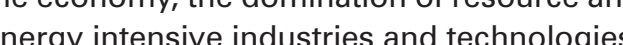
ry intensive industries and technologies, rex of production in industrial regions caused an unbalanced structure of naure usage and development management tert interconnected territorial levels (macro, meso, micro). This system is generally ineffective and environmentally hazardous.

If the recent action plans of the Cabinet of Ministers of Ukraine on decentralization aimed at reforming of the planning system take place this may potentially shift plannin process to local levels (if fully implemented). will enable cities to prioritize their own economic and social needs. This will help to cre ate a more transparent system, securing the ave count the actur sitution in cites where population is growing or decreasing. Such changes will grequie significant funding and capaity willing a the local levet (mico or cal) In adition, there is an unel (micro or che line, so that local authe extent of cilies deche

Beginning 2015, the project "Integrated urban development in Ukraine" is implemented, in order to study the real situation at the city evel (micro level or local level) in Ukraine,
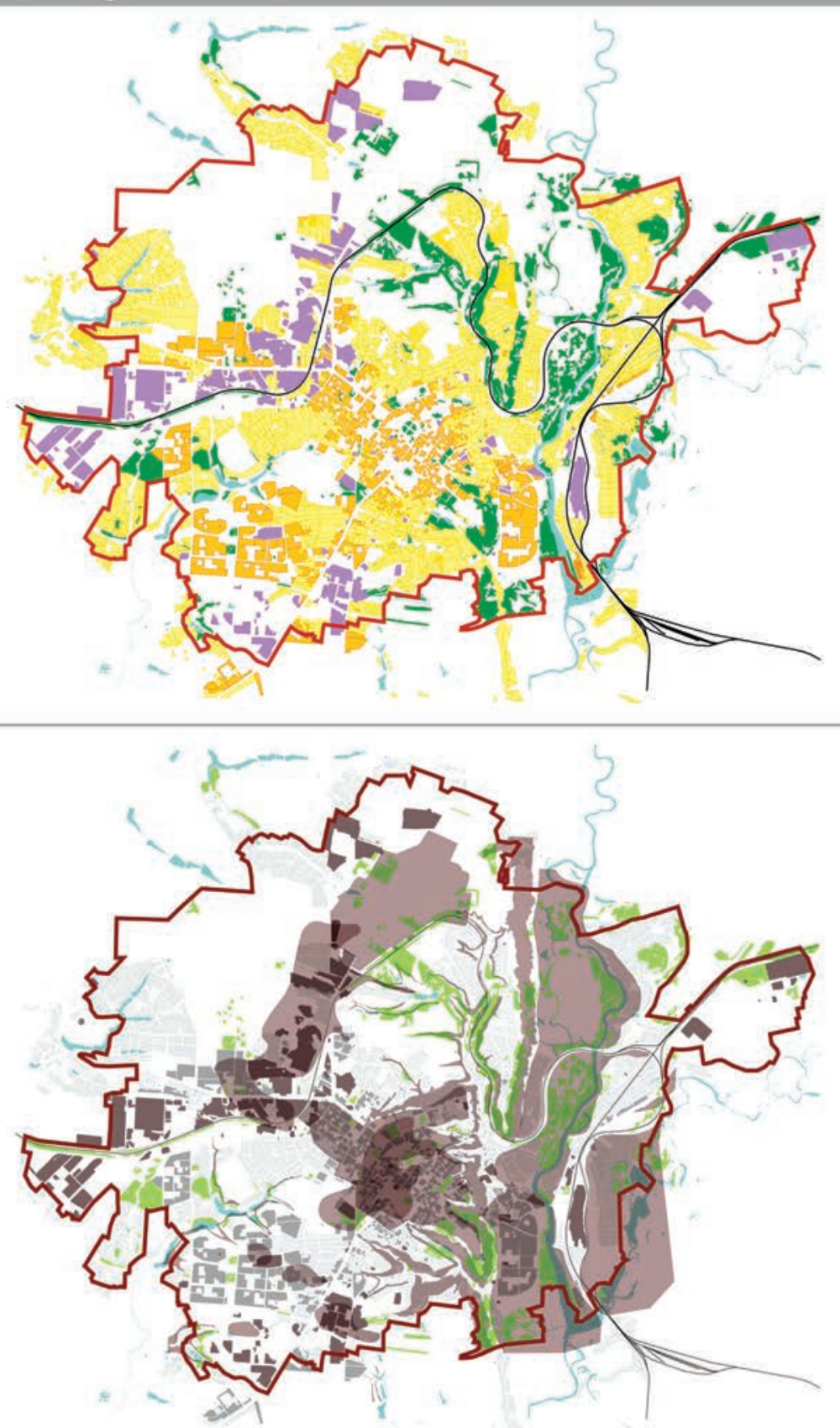

\section{Models of spatial development}

linear along the

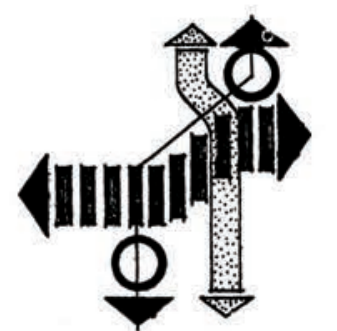

inear along the

urban axis

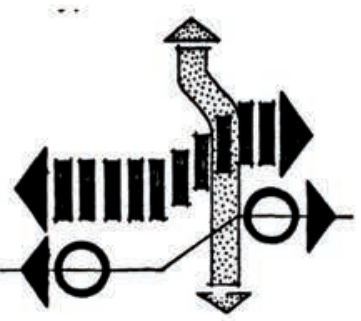

multi-axis

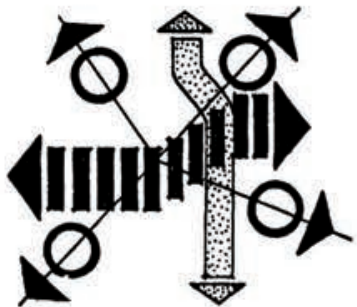


includes the cities of Vinnitsa, Chernivtsi, Zhytomyr and Poltava. The project customer is the German Federal Ministry for Economic Cooperation and Development (BMZ) and the State Secretariat for Economic Affairs of the Swiss Confederation (SECO). Based on the research, the strengths and weaknesses of cities (SWOT-analysis) are studied, based on the participation process the development potentials are defined prospects of development with wide public involvement are determined, they will be considered in the future when are veloping city planing cocumentation and first of all veloping

plans.
But above all, for development of master plans it is necessary to determine the latest methodological approaches in spatial development of Ukrainian cities. Existing methodological tial develope bases foresee the developmen a possible increase in population, on this basis, calculations

The demographic situation in most Ukrainian cities remains tense. The rapid decline in population (by $13 \%$ throughout the country over the past two decades) is associated with a general trend towards aging, a significant decline in fertility (from 1990 to levels that do not provide reproduction of the population), and, partially, due to emigration. And although the population is decreasing throughout the territory, the demographic movement in different regions is uneven. There are significant differences in the country: population decline in the East over the past two decades has been faster, while in the West it is slower, and several cities, including Kiev, continue to grow. At the same time, despite the increasing aging of the urban population in all regions, the East loses young people faster than the rest of the regions. Similar changes are observed in the field of economic activity both within the regions and interregional. In the narrow sense of the term, urbanization in Ukraine continues, despite the decline in the number of its urban population (because the rural population declined even faster). The eastern and southern regions, which at the time of the collapse of the Soviet Union agions, had a high level of urbanization, demonstrated a slower pace of urbaization over the past two decades, whereas in the West, where the rurat popultion was historicaly previ the West, where the rural popultio was historically prevalent, and to a lesser extent pop res of un

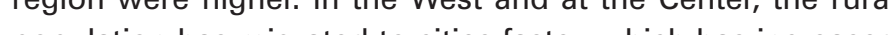
population has migrated to cities faster, which has increased the share of the un ban population in the West. The population of more than $80 \%$ of Ukrainian cities has declined, but the share of cities with shrinking population is disproportionately higher in the East and share of cities with growing population is higher in the West.

An important feature for Ukrainian cities and their economies is a feature of the mono functionality of the industrial sector. It is this heritage that influences investment processes, the potential attractiveness of the urban economy. In Ukraine, "monocities" are defined in the legislation as those, "the specialization of labour force or economically active population is defined mainly by the enterprises of one or two major sectors of the economy, forming the revenue part of the city budget, ensure the functioning of social infrastructure and other ob- jects of life support of the population". Currently, there are 111 Ukraine. Monofunctional cities are the largest in the Eastern part of Ukraine. There are 27 such cities there. This can be partly explained by the decision on the specialization of the eastern part of Soviet Ukraine for the production of coal, metallurgy, heavy engineering, chemical industry, etc. due to the large ing, chemical industry, etc. due to the large volume of natural resources of the Eastern ban planing was widely upproach to urban planing was we induritizeans of industrialization and teritorial management, which focused mainly on the needs of large industral enterprises and the corresponding infrastructure.

The next challenge to take into account is the existing spatial organization of Ukrainian cities. From an economy built around industria enterprises to a service-based economy, with the financial sector and the creative industry in the forefront of these changes. The large number of sub-sectors of the services sector: retail, real estate trade, information and communication technologies, and others have developed significantly. At the forefront are requirements for creation of a comfortable housing environment based on the principles of sustainable ecologically balanced development.

Particular attention is required for the tourism industry due to the existing historical and cultural potential in Ukraine and the number of cities with the status of historic cities (1). As of 2013, the State Register of Fixed Monuments of Ukraine included 4719 monumuof which 891 were of nat 4719 monuments, and 3828 were of locat importance, value most valuable examples of cultural and historica 7 UNESCO protect by UNESCO. There are In the Cen In the Central region of Ukraine is located the historical city of Poltava. The city is a participant of the GIZ project "Integrated urban development in Ukraine". The SWOT analysis process has been completed, right now is being developed an appropriate Concept for long-term urban development for the period up to 2030 . The city has lost its population in recent years, the economy has all the sign of stagnation, there was a need to improve the comfort living areas, significant areas of industrial use demand revalorisation, etc. In addition, the city has significant historical cultural and tourist potential. Particularly important is the fact that the cultural paradigm of the theory of modern urban planning is relevant to the present day (2). The Concept defined the prospect of city development requires the use of the latest methodological approaches in the master plan, taking into account the state of arts and existing potential.

The latest methodological approaches need to be implemented at all three interconnected levels of planning in Ukrain (macro level - national meso level - regional micro level - Iocal (city) level). Particularly important is the local (city) level which, in case of implemented measures of Governme of Decentralization Program, becomes the main one Such a Decentrazion one. Suc a a design. It includes a comprehensive, continuous monitorin process at all teritoral levels and the corresponding project response. The introduction of permanent spatial (urban planning) design will provide an opportunity to respond promptly to changes occurring in the environment, to determine the value of each phenomenon in real time, which allows you to switch from statically fixed properties and rigidly proposed priorities in the decision-making process to a dynamic picture of phenomena, properties and suggested priorities. Such approach implemented on the basis of geoinformation technol-

III. 2. View of Poltava city

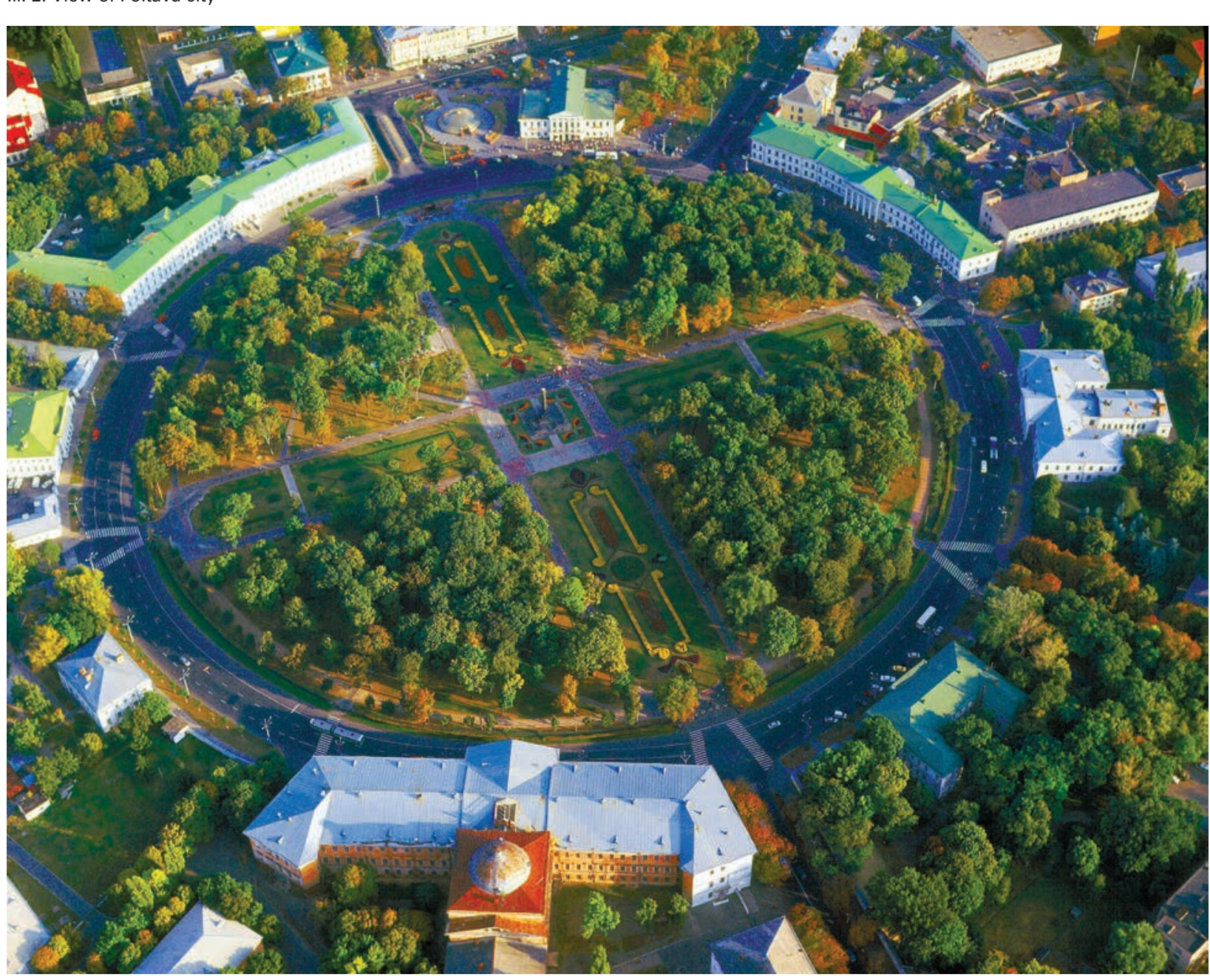

ogies, will increase the importance of urban planning monitoring, will make transparen urban planning, building processes, wide and unbiased involvement of the public will occur with the establishment of on-line platforms,

At the various "vertical" territorial levels, (state, region, local level), the priority probems of the macro level incide with the problems of the meso- or micro-territorial levels. This means that priority issues may not go from one level to the next principle letail Following ( level, the following levels can determine their ave prions. The top-down commication own priorites. The top-dow comign sequences detaling this distive design sequences vance dis for of spatial (urban planning) design allows us analyzed territorial problems and the formufore the transite its project approval. Thereto take into account the phenomenality of the 
lation of priorities, depending on the landscape-ecological and socio-economic properties of the territories (3). The type of interconnections in the object structure "horizontally" involves the necessary functional and thematic filling of design decisions, depending on the identified problems, formulated priorities and objectives. The range of decisions on the "horizontal" covers all levels and can range from the disclosure of economic and environmental problems and up to sociocultural (including aesthetic-artistic, ethnographic, etc.).

The development of the city master plan is important for modelling the prospects of spatial development on the basis of the phenomenal nature of the analyzed territorial problems. On the example of the city of Poltava during the master plan development process (2012) three basic models of spatial development were considered (fig. 1.) Such models are the basis for formulating the Concept of spatial development of the city. Territorially-spatial models of the city's development are agreed with relevant plans for socio-economic development. The next step in the methodology of permanent spatial (urban planning) is the technological aspects of urban design. All previous ideology of the formation of project ideas, decision-making and their implementation was based on paper mentality ("paper drawings") of all participants of the urban development process, beginning from designers, construction organizations, local governments and up to the final consumer (investor). Paper mentality is based on the visualization of certain spatial solutions in accordance with certain rules and standards. The gradual transition of GIS design technology to the digital basis of graphic materials greatly extends the possibilities of both designing and subsequent use of urban planning documentation into implementation practices. Back down from the traditional master plan form (change of regulatory requirements, DBN) and the transition to automated management of territories (geographic information management areas).

Modern GIS technologies integrate in a single information environment heterogeneous information about urban facilities and the environment (changing factors and changing conditions can be recorded and brought to a single time events such as: growth and qualitative changes in the population, change of resources, environmental pollution, economic development, etc.), allowing it to be visualized. Conducting project monitoring with the use of GIS gives a fundamentally new level of urban planning. The concept of spatial development of the city in the system of adjacent territories (OTG) and land use plan (land-economic arrangement) form the basis and content of the new city master plan. Saturation of the next relevant detail of the master plan takes place on the basis of continuously ongoing urban monitoring with the use of information resources of the city cadastre. At the same time there is an open process in the information space (on-line platform, community participation in the discussion of design decisions, test-poll, etc.). City planning monitoring and city planning cadastre (land cadastre) become the basis to form the system of spatial and urban planning limitations that become a program for further detailed elaboration of urban planning documentation, separate complexes and structures.

For the cities of Ukraine, the latest methodological approach is to apply the dynamic methodology of permanent spatial (urban planning) design. It provides a comprehensive, continuous monitoring process at all territorial levels and appropriate project response, creating conditions for development of a sustainable, comfortable living environment.

\section{BIBLIOGRAPHY}

[1] The list of historical settlements of Ukraine (cities and citylike settlements) [Electronic resource]. - Access mode: http://www.heritage.com.ua/

[2] I.O. Fomin The fundamentals of the city planning theory. Manual. - Kyiv: Naukova dumka, 1997.- 192 p.

[3] V. M. Vadimov Application of the spatial information sustems in territory planning (on the example of Ukrainian river basins) // The problems of the theory and history of Ukrainian architecture. - Odessa: OGASA, "Druk" - 2001. Issue 2.- p. 100-103. 